\title{
AFRODESCENDIENTES: OTRO CASO DE GARANTISMO DE LA CORTE CONSTITUCIONAL COLOMBIANA*
}

\section{PEOPLE OF AFRICAN DESCENT: ANOTHER CASE OF GUAREANTEE-ISM OF THE COLOMBIAN CONSTITUTIONAL COURT}

\author{
Viridiana Molinares Hassan*** \\ Fecha de recepción: 18 de febrero del 2013 \\ Fecha de aceptación: 5 de mayo del 2013
}

\section{Para citar este artículo / To cite this article}

Molinares Hassan, Viridiana, Afrodescendientes: otro caso de garantismo de la corte constitucional colombiana, 127 Vniversitas, 189-221 (2013)

doi:10.1144/Javeriana.VJ127.aocg

* El artículo hace parte del proyecto de investigación "Derechos y justicia constitucional" que dirige la autora dentro de la línea de investigación de Asuntos públicos y administración de justicia del Grupo de Investigación de Derecho y Ciencia Política (GIDEP) de la Universidad del Norte.

** Doctora en Derecho Público y Filosofía Jurídico-Política de la Universidad Autónoma de Barcelona, España. Magíster en Literatura Comparada y Estudios Culturales de la Universidad Autónoma de Barcelona, España. Magíster en Desarrollo Social de la Universidad del Norte de Barranquilla. Diplomada en Derechos Humanos y Derecho Internacional Humanitario de American University en Washington D. C. Directora de la Maestría y Especialización en Derecho Público de la Universidad del Norte. Profesora investigadora, miembro de los grupos de investigación en derecho y ciencia política, y sociología jurídica de la Universidad del Norte y del Grupo Libertad y Seguridad; Transformaciones del Estado, de la Universidad Autónoma de Barcelona. Correo electrónico: vmolinar@uninorte.edu.co 


\section{RESUMEN}

En este artículo presentamos un análisis de la Sentencia de la Corte Constitucional colombiana SC-931/2009, mediante la cual la Corte se declara inhibida para fallar en un caso de revisión de constitucionalidad de la Ley de 21 de mayo de 1851, con la cual se abolió de manera definitiva la esclavitud en Colombia.

El interés en presentar este caso radica en que se demuestra, una vez más y a partir de un caso concreto, el alcance del garantismo judicial en el marco de la consolidación del Estado constitucional, paradigma acogido en Latinoamérica a partir de la expedición de las constituciones de la década de los años noventa, que han dado lugar al desarrollo del nuevo constitucionalismo latinoamericano. De otra parte, unido a la presentación de las particularidades del caso, nos interesó resaltar la labor pedagógica que está realizando la Corte, recurriendo, incluso, al análisis literario, dando un claro ejemplo de integración de disciplinas en su proceso de protección judicial; además de poner en evidencia su influencia en la formulación de leyes y políticas públicas dirigidas a la protección de grupos históricamente discriminados.

Palabras clave autora: Esclavitud, garantismo judicial, Estado constitucional.

Palabras clave descriptor: Garantías constitucionales, esclavitud, derecho constitucional, derechos personales, Colombia. 


\section{ABSTRACT}

This paper presents an analysis of the Judgment of the Colombian Constitutional Court SC-931/2009, by which the Court declares inhibited to fail in a case review of the constitutionality of the Law of May 21, 1851, with which slavery was definitively abolished in Colombia.

The present interest in this case is that it demonstrates once again and from a specific case, the scope of judicial guarantee-ism under the consolidation of the constitutional state, accepted paradigm in Latin America from the issuance of the constitutions of the decade of the nineties, which have resulted in the development of the new Latin American constitutionalism. Furthermore, together with the presentation of the particular case, we were interested in noting the educational work being done by the Court, resorting even to literary analysis, giving a clear example of integration of disciplines in the process of judicial protection, in addition highlighting their influence in the formulation of laws and public policies for the protection of historically discriminated groups.

Keywords Author: Slavery, legal guarantees, constitutional state.

Keywords plus: Constitutional collateral, slavery, constitutional law, personal rights, Colombia.

\section{SUMARIO}

INTRODUCCIÓN.- I CUESTIONES PREVIAS AL ANÁLISIS DE LA SENTENCIA C-931/2009.- A. Análisis jurisprudencial.- B Fundamentos de la decisión de la Corte.- $C$. Criterios para revisar una norma derogada.D. Fundamentos y alcance de la aclaración de voto.- E. Fundamento del salvamento de voto.- $F$. Reglas de revisión de constitucionalidad frente a omisiones legislativas.- G. Deber de reparación del Estado.- CONSIDE-

\section{RACIONES FINALES.}




\section{INTRODUCCIÓN}

La constitucionalización del ordenamiento jurídico ${ }^{1}$ es una expresión que desde hace algún tiempo se ha arraigado en el lenguaje de los juristas y de los ciudadanos. De esta conceptualización se han derivado nuevos imaginarios sociales sobre lo que es el Estado constitucional ${ }^{2}$, la Constitución ${ }^{3}$ y la interpretación que de ella hacen los tribunales constitucionales ${ }^{4}$.

Peter Haberle explica que la interpretación es un proceso público que se proyecta al futuro, provocando transformaciones en la "sociedad abierta de intérpretes constitucionales".

1 En el prólogo que hace Miguel Carbonell a la obra de Gustavo Zagrebelsky, Historia y constitución, expone que de acuerdo a Riccardo Guastini "por constitucionalización del ordenamiento jurídico podemos entender un proceso de transformación de un ordenamiento, al término del cual, el ordenamiento en cuestión resulta totalmente impregnado por las normas constitucionales. Un ordenamiento jurídico constitucionalizado se caracteriza por una Constitución extremadamente invasora, entrometida, capaz de condicionar tanto la legislación como la jurisprudencia y el estilo doctrinal, la acción de los actores politicos así como de las relaciones sociales". R. Guastini, Teoría e ideología de la interpretación constitucional, $2^{\mathrm{a}}$ ed., Trotta, Madrid (2010).

2 Según Gustavo Zagrebelsky "el nuevo Estado constitucional, no representa un simple perfeccionamiento del Estado de Derecho democrático, sino su transformación radical y superadora, y tal transformación no puede dejar de afectar a la filosofía nacida al calor de éste último; por eso la supervivencia ideológica del positivismo jurídico es un ejemplo de la fuerza de la inercia de las grandes concepciones jurídicas, que a menudo continúan operando como residuos, incluso ya han perdido su razón de ser a causa del cambio de las circunstancias que originariamente las habían justificado". L. Prieto Sanchís, Constitucionalismo y Positivismo, $2^{a}$ ed., Ed, BEFDP. México (1999).

3 De acuerdo al nuevo paradigma sobre la ciencia jurídica que presenta Luigi Ferrajoli, una Constitución es un sistema de reglas, tanto sustanciales como formales, que tiene como destinatarios propios a los titulares del poder. Bajo este modelo no solo representan el perfeccionamiento del Estado de derecho, sino además constituye un programa político para el futuro: la imposición a todos los poderes imperativos negativos y positivos como fuente para su legitimación y su deslegitimación. Por así decirlo, constituyen utopías del derecho positivo que, a pesar de no ser realizables perfectamente, establecen las perspectivas del derecho mismo en dirección de la igualdad de los derechos fundamentales. L. Ferrajoli, Democracia y garantismo, Ed. Trotta, Barcelona (2009).

4 Sobre el problema de la interpretación en el derecho, en el marco del nuevo paradigma del Estado constitucional, Riccardo Guastini (2010, 29, 31-32) plantea dos ambigüedades: "la primera suele hacer referencia a la atribución de significado a un texto normativo o bien a la calificación jurídica de un supuesto de hecho concreto. Debemos por tanto distinguir entre: a) La interpretación 'en abstracto', que consiste en identificar el contenido de significado — es decir, el contenido normativo (la norma o normas) - expresado por, ylo lógicamente implícito en, un texto normativo (una fuente del derecho) sin referencia a algún supuesto de hecho concreto. b) La interpretación 'en concreto' que consiste en subsumir un supuesto de hecho concreto en el campo de aplicación de una norma previamente identificada 'en abstracto'. La segunda ambigüedad de interpretación se refiere al vocablo 'interpretación' que hace referencia en algunas ocasiones a un acto de conocimiento, en otras a un acto de decisión y en otras más a un acto de creación normativa. Por lo tanto habría que distinguir entre la interpretación cognitiva, decisoria y creativa".

5 P. Haberle, Pluralismo y constitución, Ed. Tecnos, España, 89 (2002). 
Miguel Carbonell, refiriéndose a la afirmación de Haberle, plantea que "para que el activismo social [en materia de interpretación constitucional] se pueda dar es necesario no solamente que la sociedad o algunos grupos de sus grupos se mantengan alerta en la defensa de sus derechos, sino también que el ordenamiento jurídico permita traducir en pretensiones procesales esa vigilancia". Resalta además que este proceso puede presentarse como algo obvio en los países avanzados, pero supone un problema de considerables dimensiones en países que sufren de graves retrasos en la evolución de sus ordenamientos jurídicos 6 .

Esta experiencia, que se expande en el constitucionalismo latinoamericano, ha llevado a algunos investigadores a plantear el desarrollo de un nuevo constitucionalismo en esta parte de Occidente 7 , convirtiéndose en el punto de convergencia de los estudios de académicos que de manera simultánea, en esta última década, asisten a la consolidación de este proceso en Latinoamérica, y al decaimiento del Estado bienestar europeo; no obstante se proponga, por parte de autores como Luigi Ferrajoli, el constitucionalismo universal, que Isabel Turégano analiza desde el paradigma garantista, que también propone este autor ${ }^{8}$.

6 M. Carbonell, en: G. Zagrebelsky, Ed., Historia y Constitución, Trotta, Madrid, 24-25 (2011).

7 Sobre el nuevo constitucionalismo latinoamericano Roberto Viciano Pastor y Rubén Martínez Dalmau explican sus fundamentos teóricos, distinguiéndolo del neo-constitucionalismo, como corriente que surge con los Estados constitucionales de mitad del siglo XX, y resumiéndolo en que es el producto de las nuevas constituciones de los Estados constitucionales latinoamericanos, sustentadas en el poder constituyente primario, es decir es el producto de las constituciones democráticas. Estos autores explican sobre el tema: "El nuevo constitucionalismo mantiene las posiciones sobre la necesaria constitucionalización del ordenamiento jurídico con la misma firmeza que el neoconstitucionalismo y plantea, al igual que éste, la necesidad de construir la teoría y observar las consecuencias prácticas de la evolución del constitucionalismo hacia el Estado constitucional [...] el nuevo constitucionalismo busca analizar, en un primer momento, la exterioridad de la constitución, es decir, su legitimidad, que por su propia naturaleza sólo puede ser extrajurídica [...] el nuevo constitucionalismo es, principalmente, una teoría (democrática) de la constitución" y siguen explicando sobre el caso latinoamericano "[...] en América Latina ha pasado a convertirse en práctica, realizada a través de determinados procesos constituyentes latinoamericanos que han producido nuevas constituciones. En efecto, a través de los últimos procesos constituyentes se han legitimado textos constitucionales que han buscado, en un maremágnum de obstáculos y dificultades, no sólo ser reflejo del poder constituyente, sino, a continuación, permear el ordenamiento jurídico y revolucionar el statu quo de sociedades en condiciones de necesidad [...]Estos productos procesos con sus productos, las nuevas constituciones de América Latina, conforman el contenido del conocido como nuevo constitucionalismo latinoamericano". R. Viciano \& R. Martínez Dalmau, Fundamento teórico del nuevo constitucionalismo latinoamericano, en: Estudios sobre el nuevo constitucionalismo latinoamericano, E. Tirant Lo Blanch, Valencia, 20-21 (2012).

8 De acuerdo a Luigi Ferrajoli el garantismo está dirigido a establecer las técnicas de garantías idóneas para asegurar el máximo grado de efectividad a los derechos constitucionalmente 


\section{Para Turégano,}

[...] la versión garantista del constitucionalismo de Ferrajoli recupera y renueva la pretensión ilustrada y contractualita de hacer de cualquier poder un instrumento al servicio de los derechos, ampliando esta exigencia a todos lospoderes y a todos los niveles. Así concebido, el constitucionalismo no es sólo una conquista y un legado del pasado sino, ante todo, un programa para el futuro, en el sentido de que los derechos deben ser garantizados y satisfechos de modo efectivo y de que el constitucionalismo debe ser extendido en una tripe acción: primero hacia la garantía de todos los derechos, no sólo los derechos políticos $y$ de libertad, sino también a los sociales; segundo, frente a todos los poderes, no sólo públicos sino también privados; $y$, tercero, a todos los niveles, no sólo en el derecho estatal sino también en el internacional.

Bajo este contexto, consideramos una obligación, presentar el caso del desarrollo constitucional colombiano desde el garantismo de la Corte Constitucional (Corte) que da cuenta de un interesante y dinámico proceso de interpretación. Proceso en el que resalta una actitud innovadora y liberal de los primeros jueces progresistas que la integraron, y un esfuerzo de articulación con la producción legislativa y con las políticas públicas de sus actuales integrantes. Estos últimos, en el ejercicio de sus facultades de control de constitucionalidad, han exhortado a las autoridades legislativas y administrativas a realizar cambios través de los cuales se materializan los principios constitucionales para todos los asociados haciendo énfasis, como en el caso que a continuación analizamos, en las poblaciones históricamente discriminadas ${ }^{10}$.

reconocidos. El garantismo se opone a cualquier concepción tanto de las relaciones económicas, como de las políticas, tanto de las reglas de derecho privado como las de derecho público, fundada en una ilusión de un "poder bueno" o de una observancia espontánea. Este autor distingue varios tipos de garantismo: patrimonial: sistemas de garantías destinados a tutelar la propiedad y demás derechos patrimoniales; liberal: para designar las técnicas de la defensa de los derechos de libertad; social: destinado a la satisfacción de los derechos sociales; internacional: para tutelar los derechos humanos establecidos en las declaraciones y convenciones internacionales, por el momento casi inexistentes. De igual forma realiza una distinción entre garantías primarias y secundarias, señalando que las primeras consisten en las obligaciones o prohibiciones que correspondan a los derechos subjetivos garantizados, y las segundas en las obligaciones, por parte de los órganos judiciales, de aplicar la sanción o declarar la nulidad cuando se constaten, en el primer caso, actos ilícitos, y en el segundo, actos no válidos que violen derechos subjetivos, y con ellos, sus correspondientes garantías primarias. Finalmente estable una relación entre el garantismo y el constitucionalismo afirmando que el garantismo, no es más que la otra cara del constitucionalismo. L. Ferrajoli, Democracia y garantismo, Ed. Trotta, Barcelona (2009).

9 I. Turégano, en: Marcilla, Gema, 221-222 (2009).

10 Resaltamos aquí la Sentencia C 577 de 2011 mediante la cual se reconoció la familia entre 
En este contexto, la Corte da un claro ejemplo de la pretensión de corrección del derecho a la que se refiere Robert Alexy cuando planteando la polémica relación entre derecho y moral, afirma que los fallos judiciales, en clave anti-positivista, se orientan a decidir correctamente.

\begin{abstract}
En el ámbito de apertura este deber jurídico se refiere también a la aplicación correcta de normas morales; ya que por definición, en el ámbito de apertura no se puede decidir sólo sobre la base de las normas de derecho positivo, y el recurso exclusivo a consideraciones de conveniencia no es suficiente para resolver correctamente un problema jurídico ${ }^{11}$.
\end{abstract}

Es así como desde la expedición de la Constitución en 1991, que ha provocado una transformación cultural reflejada en "la conciencia de los derechos humanos, el pluralismo y la gradualidad como forma de pensamiento constitucional"12 hasta la fecha, el legislador colombiano ha tenido que ocuparse en la expedición de leyes a través de las cuales se reconocen beneficios a favor de la población afrodescendiente; en el mismo sentido, el Gobierno Nacional ha incluido en sus políticas públicas objetivos orientados a la inclusión de esta población en espacios sociales, políticos y culturales ${ }^{13}$,

parejas del mismo sexo y se exhortó al Congreso a legislar sobre el carácter de la unión civil entre esta población. La Corte dispuso en esta sentencia: "toda pareja de personas del mismo sexo tiene el derecho a constituir una familia mediante un acto contractual de carácter marital, solemne y formal. Las uniones de parejas de personas del mismo sexo son familia, por tanto, tienen derecho a la plena protección que concede el artículo 42 de la Carta Politica a esta institución, núcleo básico de la sociedad" y dispuso en los numerales cuarto y quinto de la parte resolutiva de la sentencia: "CUARTO.- EXHORTAR al Congreso de la República para que antes del 20 de junio de 2013 legisle, de manera sistemática y organizada, sobre los derechos de las parejas del mismo sexo con la finalidad de eliminar el déficit de protección que, según los términos de esta sentencia, afecta a las mencionadas parejas. QUINTO.- Si el 20 de junio de 2013 el Congreso de la República no ha expedido la legislación correspondiente, las parejas del mismo sexo podrán acudir ante notario o juez competente a formalizar y solemnizar su vínculo contractual". (SC 577 de 2011. M. P. Gabriel Mendoza Martelo).

11 A. Robert \& E. Bulygin, La pretensión de corrección del derecho: la polémica sobre la relación entre derecho y moral, Ed. Universidad Externado de Colombia, Serie de Teoría jurídica y filosofía del derecho, No. 18 Colombia, 37 (2001).

12 R. Arango, Derechos, constitucionalismo y democracia, Universidad Externado de Colombia, Serie de Teoría jurídica y filosofía del derecho, No 33, Colombia, 143 (2004).

13 Nos referimos aquí a la Ley 70 de 1993, que se expidió para dar cumplimiento al artículo 55 de transitorio de la Constitución, cuyo objeto fue reconocer a las comunidades negras que han venido ocupando tierras baldías en las zonas rurales ribereñas de los ríos de la Cuenca del Pacífico, de acuerdo con sus prácticas tradicionales de producción, el derecho a la propiedad colectiva. También debemos anotar que se han expedido varios decretos reglamentarios para la protección de los derechos de estas comunidades, se cuenta además con el Documento Conpes 3310 de 2004 y con las observaciones de la Comisión Interamericana de Derechos Humanos sobre los derechos de los afro descendientes de marzo de 2009. En el campo judicial resalta 
evidenciando la protección a las minorías culturales, tema que ha tomado una gran relevancia en los últimos años en la medida en que se han ido acentuando el pluralismo y la complejidad de las sociedades contemporáneas ${ }^{14}{ }^{15}$.

Cabe preguntarse si estos procesos legislativos y administrativos corresponden a iniciativas propias de estas ramas, si son resultado de la fuerza material de la Constitución o si por el contrario, o complementariamente, derivan de decisiones de la Corte, relación que intentaremos establecer con la sentencia analizada en este artículo $^{16}$.

\section{CUESTIONES PREVIAS AL ANÁlisis DE LA SENTENCIA C-931 DE 2009}

La Corte, mediante Sentencia C-931/09, con ponencia de la magistrada María Victoria Calle, se declaró inhibida para fallar una demanda de constitucionalidad, presentada por el ciudadano Antonio Eduardo Bohórquez Collazos, sobre la Ley de 21 de mayo de 1851, conocida como la Ley de Libertad de Esclavos. Ajustando

el Auto 005 de 2009, mediante el cual la Corte Constitucional compila las diversas decisiones judiciales que ha expedido en procura de garantizar los derechos de los afrocolombianos. Además de contar con el Convenio 169 de la orT, que hace parte del bloque de constitucionalidad y establece la consulta previa de carácter obligatorio a los afro descendientes, sobre decisiones administrativas y judiciales que los afecten, todos esfuerzos importantes pero insuficientes ante una injusticia tan grande.

14 Refiriéndose al tema de las minorías Miguel Carbonell, manifiesta que "el constitucionalismo contempla a las minorías desde una triple perspectiva. Por un lado, el constitucionalismo tutela $y$ protege los derechos de esa minoría esencial, irreductible, que es el ser humano individual, a través del reconocimiento de los derechos fundamentales; en segundo lugar, el constitucionalismo se ha encargado, desde sus origenes, de asegurar un estatus mínimo para las minorías politicas, es decir, para los grupos que no tienen el poder politico en un momento y un espacio geográfico determinados, pero que aspiran a tenerlo en el futuro; finalmente, el constitucionalismo de más reciente factura se ha preocupado por ir propiciando las condiciones para reconocer la existencia y procurar las derechos de las minorías culturales o étnicas, de aquellas que tienen una cultura o un origen étnico distinto del mayoritario dentro de un estado" (énfasis en original). M. Carbonell, 37 (2009).

15 M. Carbonell. Elementos de derecho constitucional, 2 reimpresión, Ed. Fontamara, México, 38 (2009).

16 No obstante el protagonismo de la Corte, en el contexto del desarrollo constitucional del Estado colombiano, consideramos atemperada su inclusión en las órbitas de los otros poderes, desvirtuando cualquier proceso de sobre-constitucionalización; por el contrario, afirmamos que sus límites están precisamente en la protección de los derechos fundamentales como núcleo de las actuales constituciones democráticas. Robert Alexy, refiriéndose a la constitucionalización, sobre-constitucionalización e infra-constitucionalización, señala sobre este aspecto que "una constitucionalización adecuada sólo puede construirse por el camino pedregoso y arduo de la dogmatica de los márgenes de acción. al igual que el problema de la constitucionalización, esta dogmatica se extiende más allá del ámbito de los derechos fundamentales, sin embargo, ella tiene aqui su núcleo y su punto de partida". R. Alexy, 53 (2003). 
sus facultades a las limitaciones del artículo 241 constitucional, la Corte consideró que la norma objeto de revisión carecía de objeto y al no encontrarse vigente no podía producir consecuencias jurídicas hacia el futuro.

Junto a su decisión resaltó la imposibilidad de ordenar indemnizaciones como medida de reparación en un proceso de constitucionalidad y precisó el alcance de su decisión resaltando:

La declaratoria de inhibición en el presente caso no implica desconocer en modo alguno, los graves efectos que produjo la esclavitud en las personas que la padecieron y la sufrieron, fuese cual fuese su color de piel. Tampoco implica restar importancia a la deliberación que, en democracia participativa, se ha de dar acerca de las consecuencias e implicaciones de las prácticas racistas, pasadas y presentes, así como de las medidas que se han de tomar para evidenciarlas, abolirlas, superarlas, repararlas y asegurar que no se repitan nunca más... La decisión que la Corte Constitucional adopta en la presente sentencia se limita a señalar que, en sede de revisión de constitucionalidad, esta Corporación carece de competencia para evaluar la Ley del 21 de mayo de 1851. No puede pronunciarse, especificamente, sobre si esa ley observa o no los parámetros constitucionales actuales, pues tal, no es una función que se le haya asignado, por las razones antes dichas. En todo caso, esto no obsta, en modo alguno, para que el debate se dé, como en efecto se da en la actualidad, en democracia. (SC 931/09. M.P. María Victoria Calle)

Hasta aquí podríamos decir que no habría lugar a un mayor análisis del caso; sin embargo, consideramos esta sentencia como un caso de interpretación de la Constitución bajo un modelo axiológico ${ }^{17}$ y con unas particularísimas singularidades que aportan un interesante protagonismo a la Corte en el contexto del constitucionalismo universal.

Nuestra afirmación se orienta a que la decisión de la Corte, si bien es inhibitoria, induce a que legislador y gobierno realicen

17 Acogemos aquí la categorización y conceptualización que presenta Paolo Comanducci, según la cual hoy se pueden distinguir cuatro modelos de constitución, reconociendo al primer modelo como modelo axiológico que el autor define como: "La constitución entendida como orden. Constitución designa aquí a un conjunto de fenómenos sociales (entendida esta expresión en su sentido más amplio) que, en su conjunto y dentro de la esfera jurídico - política, aparecen dotados del máximo valor intrínseco o se presentan como generadores de norma. En esta acepción, constitución no hace referencia directa a normas, sino indirecta; directamente designa un orden, es decir, un ordenamiento o una estructura de la sociedad ylo del Estado. Tal orden, en virtud del valor fundamental de que es portador, genera por sí normas que también son fundamentales (es decir, fundantes y/o jerárquicamente supremas". P. Comanducci, 161-162 (2010). 
acciones para proteger, garantizar, defender y restaurar los derechos de la población afrodescendiente, heredera de un pasado de sometimiento a una de las instituciones más denigrantes que ha concebido el hombre: la esclavitud, además de ser protagonista, en la actualidad, de un claro proceso de discriminación.

En la sentencia se pueden estudiar tres cuestiones fundamentales: el análisis desarrollado por la Corte para determinar los criterios de revisión de constitucionalidad de leyes expedidas antes de la Constitución de 1991 y sus efectos bajo esta Carta. La descripción del contexto histórico para la expedición de la Ley sobre Libertad de Esclavos, junto a la relación de las personas e historias que hicieron parte de la construcción del derecho a la libertad, que presenta en su aclaración de voto María Victoria Calle, además de la interesante relación que esta magistrada plantea entre el discurso jurídico y el análisis histórico y literario de la esclavitud y, finalmente el salvamento de voto, presentado por los magistrados Juan Carlos Henao y Luis Ernesto Vargas Silva, en el cual se extienden sobre la conceptualización de las omisiones legislativas absolutas y relativas, presentado la línea jurisprudencial desarrollada sobre el tema por parte de la Corte, además de plantear, sustentados en instrumentos internacionales de derechos humanos, el deber de reparación que le asiste al Estado colombiano frente a los afrodescendientes ${ }^{18}$.

Sobre las dos últimas cuestiones queremos resaltar la importancia que reviste la aclaración de voto de María Victoria Calle, esto debido a que en 22 años de creación de la Corte, solo dos mujeres han hecho parte de esta corporación, situación que da lugar a que se realce el papel de las mujeres en sala de justicia más importante del país.

Entre las observaciones realizadas en la aclaración de voto, la magistrada induce a la expedición de políticas públicas por parte del gobierno, resaltando que:

Dada la situación descrita actual de las comunidades negras de Colombia, varias son las dimensiones que se han de tener en cuenta para las políticas pú-

18 Las particularidades en torno a la interpretación constitucional, en este caso, nos conducen a la interpretación jurídica como un discurso racional, sobre la cual Robert Alexy ha planeado que "la interpretación, en particular del derecho constitucional (tiene) el carácter de un discurso en el que se hacen valer argumentos a los que se contraponen otros argumentos, debiendo darse finalmente predominio a los mejores argumentos". R. Alexy, 35-36 (2009). 
blicas que en materia de reparación puedan ser implementadas. Entre ellas (i) reconocer institucionalmente el crimen de esclavitudy promover el conocimiento y la memoria histórica, (ii) adoptar medidas adecuadas y necesarias tendientes a eliminar las desigualdades producto de la ausencia de restablecimiento del territorio ancestral de las comunidades afrocolombianas, en el marco del fortalecimiento de los mandatos de la Ley 70 de 1993; y (iii) de acuerdo a lo dispuesto por el Convenio 169 de la OIT, consultar previamente a las poblaciones afrodescendientes las políticas que en esta materia se establezcan. (AV. María Victoria Calle. SC- 931/2009. Negrillas fuera de texto)

De otra parte, es indispensable resaltar el uso que hace esta magistrada, para aclarar su voto, de la literatura colombiana, especialmente de la obra de Manuel Zapata Olivella. Con esto se pone de manifiesto que el discurso judicial constitucional puede hacer uso de otros lenguajes, como la literatura, para el análisis de problemáticas como la exclusión racial, sin dejar por fuera el importante precedente que en materia pedagógica representa esta aclaración, por cuanto informa al lector del desarrollo de la institución de la esclavitud en Europa, América y Colombia ${ }^{19}$.

Unido a lo anterior ocupa otro lugar de privilegio, para el análisis, el salvamento de voto de los magistrados Juan Carlos Henao Pérez y Luis Ernesto Vargas Silva, quienes, en flagrante actitud crítica frente a la decisión de la mayoría de la Corte, consideraron que con la declaratoria de inhibición para fallar la Corte "ha desperdiciado en este caso una oportunidad histórica para reconocer, a la luz de nuestra Carta Política vigente, la ocurrencia del crimen de la

19 En la aclaración de voto de la sentencia analizada y con base en datos académicos la Magistrada María Victoria Calle presenta las siguientes cifras en torno al comercio de esclavos: "durante el siglo XVI el comercio de esclavos africanos fue menor que en años posteriores (cerca de 125.000 personas) y se dirigió, en especial, hacia Europa. Durante el siglo XVII (1601-1700) el comercio de esclavos aumentó significativamente (más de un 1'300.000 personas), dirigiéndose principalmente al Brasil (41\%), luego a la América española (22\%), al Caribe inglés (20\%) y francés (12\%), y a otras colonias. El apogeo del comercio de esclavos africanos corresponde al siglo XVIII (1701-1800), llegándose a traficar con más de 6’000.000 personas. Es este siglo en el cual va a ingresar la mayor parte de futuros colombianos descendientes del África. Aunque el comercio no se centró en América española (9\%), si fue considerable. La trata seguía estando centrada en Brasil (31\%) en el Caribe inglés (23\%) y el Caribe francés que aumentó considerablemente (22\%). La América inglesa tenía un (6\%). El siglo XIX fue el declive del negocio. Aunque disminuyó drásticamente, seguía siendo muy amplio y se concentró aún más en Brasil y en la América española. En el Caribe inglés, los debates en el Parlamento llevan a que se concluya con el negocio. Entre el año 1801 y el 1870 se comerció con más de 1'890.000 personas provenientes del África, concentrándose la trata en Brasil (60\%) y la América española (32\%). En Inglaterra y Francia disminuyó por el triunfo interno de los grupos abolicionistas de uno y otro lado” (SC - 931/2009. AV. M. María Victoria Calle). 
esclavitud y sus consecuencias principalmente entre la población afro descendiente" (SV. M.M. Juan Carlos Henao Pérez y Luis Ernesto Vargas Silva.Sentencia C-931/2009).

Los magistrados, en su salvamento de voto, consideraron que la Corte "Al haberse pronunciado de fondo sobre el asunto, hubiera contribuido institucionalmente, a partir de los estándares normativos superiores, a visibilizar las consecuencias históricas, en términos de exclusión y desigualdad, de la trata esclava. Así, con la decisión adoptada, se perdió un espacio para reducir la asimetría que existe entre la relativamente poca atención que la justicia constitucional colombiana le ha prestado a las reivindicaciones afrodescendientes, respecto de otras que sí han merecido prolijos y elaborados análisis de esta Corporación" (SV. M.M. Juan Carlos Henao Pérez y Luis Ernesto Vargas Silva. Sentencia C-931/2009) ${ }^{20}$.

Finalmente, la elección de la sentencia objeto de análisis atendió a su carácter innovador y tal vez único en constitucionalismo comprado en el sentido de que se puso en movimiento el aparato judicial, a través del ejercicio de un derecho político, como se considera en el país la presentación de una acción pública de inconstitucionalidad, para la revisión de una norma del siglo XIX frente a una constitución expedida hace veintidós años.

Bajo las circunstancias descritas, consideramos que esta sentencia es ejemplo del activismo de la Corte y de su frontal compromiso con la protección de los derechos fundamentales - leyes de los más débiles $^{21}$ - y, junto al proceso de enseñanza, de los actuales fun-

20 Consideramos que la última afirmación de los magistrados se refiere a la visibilidad que se le ha otorgado, desde la expedición de la Constitución de 1991, a las comunidades indígenas de Colombia, que difiere de la que se le ha otorgado a la población afrodescendiente. Podemos, por ejemplo analizar la relación normativa desarrollada a favor de las comunidades indígenas en la obra de Gonzalo Aguilar, Justicia constitucional y modelos de reconocimiento de los pueblos indigenas. Mientras que carecemos de desarrollos legislativos significativos a favor de la población afrodescendiente.

21 Acogemos aquí el concepto de derechos fundamentales presentado por Luigi Ferrajoli, no nos detenemos en las cuatro tesis que sobre el tema presenta sino en el concepto general que lleva a concluir que estos derechos, como lo afirma este autor, son los derechos del más débil. "Son derechos fundamentales todos aquellos derechos subjetivos que corresponden universalmente a todos los seres humanos en cuanto dotados del status de personas, de ciudadanos o personas con capacidad de obrar; entendiendo por derecho subjetivo cualquier expectativa positiva (de prestaciones) o negativa (de no sufrir lesiones) adscrita a un sujeto por una norma jurídica; $y$ por status la condición de un sujeto, prevista asimismo por una norma jurídica positiva, como presupuesto de su idoneidad para ser titular de situaciones jurídicas y/o autor de los actos que son ejercicio de estás...los derechos fundamentales se afirman siempre como leyes del más débil en alternativa a la ley del más fuerte que regía y regiría en su ausencia”. L. Ferrajoli, 37,54 (2010). 
damentos del derecho constitucional colombiano, sustenta todo el andamiaje alrededor de los Estados democráticos y constitucionales fundados en la dignidad humana ${ }^{22}$, principio con el cual se imponen límites a los poderes constituidos a la vez que se reafirma el deber de restauración a las poblaciones históricamente discriminadas.

Realizamos el análisis presentando los argumentos de la Corte para llegar a su decisión; los aspectos que consideramos más importantes de la aclaración de voto y el salvamento de voto que hicieron parte de la sentencia analizada; para finalmente presentar unas consideraciones sobre lo que este caso representa para el constitucionalismo universal desde el garantismo de la Corte Constitucional colombiana.

Antes de seguir con nuestro análisis agradecemos a Aquiles Arrieta, magistrado auxiliar de la Corte, quien, con la pasión que lo caracteriza, nos dio a conocer el tema que aquí presentamos.

\section{A. Análisis jurisprudencial}

En el 2012 se tramitaron en el Congreso de la República dos importantes proyectos de ley orientados a otorgar espacios de participación a favor de la población afrodescendiente. Se trata del proyecto de reforma a la Ley 5 de 1992, con el cual se daría paso a la creación de una comisión legal, en cada una de las Cámaras que integran el poder legislativo, para la protección de esta población; y del proyecto de ley mediante el cual se "reglamenta la adecuada y efectiva participación de la población negra afrocolombiana en los niveles decisorios de las diferentes ramas y órganos del poder público”.

Estos espacios de participación podrían considerarse, como otros intentos anteriores, la materialización del Estado constitucional2 ${ }^{23}$,

22 Sobre el alcance de la dignidad humana, explica Luis Cruz, citado a Düring y refiriéndose al caso alemán, en cuanto a las diferencias entre dignidad como valor constitucional y los derechos fundamentales sostiene: "La norma que establece la intangibilidad de la dignidad humana, así como la obligación de respeto y protección de la misma por parte de todo poder público ha de ser entendida como una norma objetiva, en concreto como el principio constitucional de más alto rango de todo el derecho objetivo, en el que existe una abstracción del sujeto de derecho individual. Según Düring mientras que todo derecho fundamental en tanto que derecho público subjetivo posee unos límites concretos, el mandato de protección y respeto a la dignidad humana tiene una validez universal e intangible. Con ello se determina una base para todo el sistema de valores que sirve como criterio interpretativo de todos los derechos fundamentales reconocidos en la Constitución". L. Cruz, 21-23 (2005).

23 Gustavo Zagrebelsky explica sobre el Estado Constitucional que: "Quien examine el derecho 
que se ha venido afianzando en Colombia desde la expedición de la Constitución de 1991, en la que se consagró como principio fundamental del Estado la diversidad étnica y cultural de la nación (art. 7. C.P.).

Sin embargo, consideramos que detrás de los espacios de participación que se están generando a favor de los afrodescendientes, se encuentra el inaplazable y tardío pago de nuestra deuda con sus antepasados - los nuestros - que pagaron con la degradación de su dignidad la libertad de todos ${ }^{24}$, y han sido motivados por decisiones de la Corte como las que, de manera implícita, podemos encontrar en la sentencia objeto de análisis.

La demanda de constitucionalidad que dio origen a la sentencia analizada se fundamentó, de acuerdo al actor, en que con la Ley 21 de mayo de 1851 se "desconoció el principio de dignidad humana, dado que contempló una indemnización a favor de los tenedores de personas esclavizadas, en el marco del proceso de manumisión, cosificando de esta manera a los últimos, asignándoles una condición de mercancía y perpetuando, su discriminación social".

El actor argumentó que de la ley acusada se desprende un caso de omisión legislativa relativa. Para sostener su manifestó que "la norma objeto de análisis, si bien ordenó la liberación de todas las personas esclavizadas hace más de un siglo, no estableció un sistema de indemnizaciones a favor de los manumitidos y de sus descendientes, como sí lo hizo a favor de los llamados propietarios. En este sentido, afirmó que la Ley objeto de estudio omitió, de manera deliberada, regular lo atinente a las indemnizaciones que debian recibir los libertos por los daños materiales e inmateriales sufridos como consecuencia

de nuestro tiempo seguro que no consigue descubrir en él los caracteres que constituían los postulados del Estado de derecho legislativo. La importancia de la transformación debe inducir a pensar en un auténtico cambio genético, más que en una desviación momentánea en espera y con la esperanza de una restauración. La respuesta a los grandes y graves problemas de los que tal cambio es consecuencia, y al mismo tiempo cauda, está contenida en la fórmula del Estado Constitucional. La novedad que la misma contiene es capital y afecta la posición de la ley. La ley por primera vez en la época moderna, viene sometida a una relación de adecuación, y por tanto de subordinación, a un estrato más alto de derecho establecido en la Constitución”. G. Zagrebelsky, 33-34 (2007).

24 Entre las múltiples investigaciones que dan cuenta de la historia de nuestra libertad se puede consultar: Antropología de la esclavitud, de Cluade Meillassoux, editada en México en 1990 por Siglo Veintiuno Editores; La otra historia de los Estados Unidos, de Howard Zinn, editada en México en el 2010 por Siglo Veintiuno Editores; además la compilación de artículos sobre los afro descendientes en Colombia que editó Félix Domingo Cabezas Prado con el título Castigos y torturas en la afro diáspora para el nuevo mundo, en abril del 2011. 
de la esclavitud” (SC 931/2009. M. P. María Victoria Calle. Negrillas fuera de texto).

Esta demanda fue revisada por la Corte, quien decidió declararse inhibida para fallar bajo la consideración de que se encontraba ante una demanda con carencia de objeto, además de que la ley demandada, por no estar vigente, no proyectaba consecuencias jurídicas hacia el futuro

No obstante la decisión inhibitoria, la decisión de la Corte constituye una lección sobre el alcance y los límites al poder de revisión sobre las leyes preconstitucionales por parte del juez constitucional, que nos lleva a poner en evidencia que lo que se está gestando en el Congreso es el proceso de reconocimiento de la deuda de Colombia con los afrodescendientes derivada de las observaciones del juez constitucional, entre otras circunstancias.

\section{B. Fundamentos de la decisión de la Corte}

El problema jurídico del cual partió la Corte para decidir sobre la constitucionalidad de la ley demanda fue: ¿incurrió el legislador en una omisión legislativa relativa al haber promulgado la Ley del 21 de mayo de 1851, Sobre la Libertad de Esclavos, por cuanto diseñó un sistema de indemnizaciones para los llamados propietarios de las personas esclavizadas, pero no contempló forma alguna de reparación para las víctimas del crimen de esclavitud?

Ante este problema la Corte resolvió que la Ley de Libertad de Esclavos no se encuentra vigente, ya que fue derogada por disposiciones posteriores y consideró que:

No le es dado al juez constitucional, al terminar la primera década del siglo XXI, entrar a juzgar una de las decisiones legales más controversiales y celebradas que se hubiese presentado al inicio de la historia republicana de Colombia, a mediados del siglo XIX, bajo los parámetros del orden constitucional vigente, cuando esta decisión no está vigente y no produce efectos jurídicos.

Para llegar a esta decisión revisó los siguientes aspectos relevantes dentro de su proceso de interpretación: 


\section{Criterios para revisar una norma derogada}

De acuerdo a la jurisprudencia constitucional, la Corte no puede pronunciarse sobre leyes que están por fuera del ordenamiento jurídico; sin embargo, antes de declararse inhibida para fallar, por sustracción de materia, debe establecer si la norma continúa produciendo efectos jurídicos. Si ello es así, debe proceder a pronunciarse de fondo, definiendo si el contenido normativo de la disposición derogada se ajusta o no a la Constitución Política.

Por lo anterior, la Corte, en la sentencia analizada, se refirió a dos casos en los que es incompetente para conocer una acción de inconstitucionalidad en contra de una norma, por sustracción de materia o carencia de objeto:

- Cuando la demanda se dirige contra disposiciones derogadas.

- Cuando la demanda recae sobre disposiciones que contienen mandatos específicos ya ejecutados.

En el primer caso, la Corte estableció que la derogatoria de una ley conlleva la cesación de sus efectos jurídicos, lo cual ocurre en al menos tres casos:

- Cuando una "nueva ley suprime formal y específicamente la anterior" (derogatoria explícita).

- Cuando "la ley nueva contiene disposiciones incompatibles o contrarias a las de la antigua" (derogatoria implícita).

- Cuando "una ley reglamenta toda la materia regulada por una o varias normas precedentes, aunque no haya incompatibilidad entre las disposiciones de éstas y las de la ley nueva" (derogatoria por regulación integral).

En este orden, la Corte revisó la vigencia y la posibilidad de que la ley de abolición de la esclavitud siga produciendo efectos, y consideró que aunque no ha sido derogada expresamente por ninguna norma legal posterior, no obstante, su contenido normativo o bien 
fue regulado en normas posteriores, o bien ya se agotó, al tratarse de procedimientos y actos administrativos que ya tuvieron lugar ${ }^{25}$. Frente al segundo caso, estableció que la jurisprudencia constitucional ha considerado que carece de competencia para conocer de demandas "contra leyes cuyo objeto ya se cumplió y no siguen produciendo efectos".

Enfatizando este aspecto en su decisión inhibitoria resaltó:

"Cuando se demandan normas que contienen mandatos especificos ya ejecutados, es decir, cuando el precepto acusado ordena que se lleve a cabo un acto o se desarrolle una actividad y el cumplimiento de ésta o aquél ya ha tenido lugar", dijo la Corte enfáticamente en la sentencia C-350 de 1994 que, "carece de todo objeto la decisión de la Corte y, por tanto, debe ella declararse inhibida. En efecto, si hallara exequible la norma impugnada no haría otra cosa que dejar en firme su ejecutabilidad y, habiéndose dado ya la ejecución, la resolución judicial sería inútil y extemporánea. Y si la encontrara inexequible, no podría ser observada la sentencia en razón de haberse alcanzado ya el fin propuesto por quien profirió la disposición; se encontraría la Corte con hechos cumplidos

25 Con miras a confirmar lo anterior la Corte presenta, en la sentencia objeto de análisis, la siguiente relación normativa: "La Ley del 21 de mayo de 1851, fue expedida bajo la vigencia de la Constitución de la República de la Nueva Granada de 1843. A los pocos días, y como parte del mismo proceso político, fue aprobada la Constitución de la República de la Nueva Granada en 1853 que elevó por primera vez a rango constitucional la prohibición de la esclavitud. De esta manera, dispuso en su artículo 6 que 'no hav ni habrá esclavos en la Nueva Granada'. Más adelante, este enunciado normativo fue recogido por las constituciones politicas de 1858 (artículo 11); la de 1863 (artículo 12); la de 1886 y, finalmente, la de 1991 (artículo 17). Adicionalmente, la prohibición de esclavitud también se encuentra consagrada en el bloque de constitucionalidad. La Declaración Americana de Derechos Humanos (Bogotá, 1948) estableció en su artículo $1^{\circ}$, que 'todo ser humano tiene derecho a la vida, a la libertad y a la seguridad de la persona'. Al finalizar el mismo año, en la Declaración Universal de Derechos Humanos (1948) se consagró categóricamente en el artículo $4^{\circ}$ que 'nadie estará sometido a esclavitud ni a servidumbre, la esclavitud y la trata de esclavos están prohibidas en todas sus formas'. Posteriormente, en el ámbito internacional el Pacto Internacional de Derechos Civiles y Políticos (PIDCP, 1966) estableció que 'nadie estará sometido a esclavitud. La esclavitud y la trata de esclavos estarán prohibidas en todas sus formas' (artículo $8^{\circ}$ ), y, en el interamericano, la Convención Americana sobre Derechos Humanos (San José, 1969) reiteró la prohibición (artículo $6^{\circ}$ ), con tres precisiones. Una protección especial y explícita a las mujeres ['nadie puede ser sometido a esclavitud o servidumbre, y tanto éstas, como la trata de esclavos y la trata de mujeres están prohibidas en todas sus formas (artículo 6, numeral 1)]; la aclaración de que 'nadie puede ser constreñido a ejecutar un trabajo forzoso (artículo 6, numeral 2); y la identificación de labores que a la luz de la Convención no constituyen trabajo forzoso u obligatorio (artículo 6, numeral 3)". (SC-931/2009. M.P. María Victoria Calle. Énfasis dentro del original). 
respecto de los cuales nada podría hacer la determinación que adoptase”. (SC 931/2009. M.P. María Victoria Calle. Negrillas fuera de texto)

De otra parte, señaló los propósitos de la Ley del 21 de mayo de 1851, para poner en evidencia la carencia de objeto para pronunciarse de fondo, justificando su decisión inhibitoria:

[...] la ley de libertad, tuvo dos propósitos centrales, liberar a las personas esclavizadas y organizar el pago de las indemnizaciones a los propietarios. Se decidió que el primero de enero de 1852 quedarían en libertad todos los esclavos que existieran en el territorio de la República, por lo que "desde aquella fecha gozarán de los mismos derechos y tendrán las mismas obligaciones que la Constitución y las leyes garantizan e imponen a los demás granadinos”. (Artículo 1). Para el segundo se adoptaron diversas medidas, dentro de la que se destaca la expedición por parte del Estado de unos títulos (vales de manumisión), que tenían por objeto garantizar y poder hacer efectiva la deuda que se adquirió. (SC 931/2009. M.P. María Victoria Calle. Negrillas fuera de texto)

Continúa explicando la Corte la situación actual, el amparo a la dignidad humana del actual orden constitucional y su protección a nivel internacional:

Con relación a la primera consecuencia jurídica de la Ley acusada, se ha de reiterar que las normas constitucionales vigentes, así como las cartas de derechos, internacional e interamericana, que sobrevinieron a la Ley del 21 de mayo de 1851, son las disposiciones que integralmente se ocupan en la actualidad de mantener en libertad a las personas y prohibir que sean esclavizadas hoy en día. Es el principio de dignidad humana, el concepto central del estado social y democrático de derecho, instaurado en 1991, el que excluye por completo y en todo sentido, la criminal institución de "la esclavitud". (SC 931/2009. M.P. María Victoria Calle. Negrillas fuera de texto)

Finalmente, se pronuncia sobre las indemnizaciones económicas que planteó la Ley sobre Libertad de Esclavos, estableciendo que por vía de revisión de constitucionalidad, la Corte no puede ordenar indemnizaciones económicas, además de considerar agotado el proceso indemnizatorio, que la ley planteó, a favor de los tenedores y propietarios de esclavos, enfatizando:

Las investigaciones de historia económica han permitido esclarecer que buena parte de estos pagos sí se realizaron. En todo caso, las deudas que no hayan sido satisfechas, o prescribieron por el paso del tiempo, simplemente serían 
imposibles de cobrar bajo el orden constitucional vigente. No existe por tanto, un texto normativo de la Ley de 21 de mayo de 1851 que se encuentre vigente, respecto del cual la Corte pueda pronunciarse de fondo. Por ello la Corte se inhibirá de conocer la acción de inconstitucionalidad estudiada en el presente proceso. (SC 931/2009. M.P. María Victoria Calle)

Nótese que si bien la Corte se ocupa de dos aspectos relevantes para decidir el caso: los efectos y la vigencia de la ley, su razonamiento no profundiza, como sí lo hace el salvamento de voto de los magistrados Juan Carlos Henao y Luis Ernesto Vargas Silva, en aspectos como los alcances de la Corte frente a las omisiones legislativas relativas en las que se apoya el actor, además del deber de reparación al que está obligado el Estado colombiano frente a injusticias históricas, acudiendo a estándares internacionales sobre reparaciones integrales.

\section{Fundamentos y alcance de la aclaración de voto}

La Magistrada María Victoria Calle, hizo uso de importantes referencias bibliográficas para aclarar $\mathrm{su}^{\mathrm{voto}}{ }^{26}$, que se fundamentó

26 En la aclaración de voto se presenta la siguiente relación de obras consultadas: "La bibliografía básica consultada por la Corte Constitucional que sustenta esta aclaración es la siguiente: $\mathrm{Ca}$ macho Roldán, Salvador (1925). Memorias. Editorial Bedout. Medellín, 1974. Conde Calderón, Jorge (2009). Buscando la nación. Ciudadanía, clase y tensión social en el Caribe colombiano, 1821 - 1855. Editorial, la Carreta Histórica. Medellin, 2009. Curtin, Philip De Armind (1969). The Atlantic salve trade. A census. The University of Winsconsin Press. 1969. Diaz Díaz, Rafael Antonio (2001) Esclavitud, Región y ciudad. El sistema esclavista urbano-regional en Santafé de Bogotá. Pontificia Universidad Javeriana. Bogotá, 2001. De Friedemann, Nina S. \& Patiño Roselli, Carlos (1983). Lengua y sociedad en el palenque de San Basilio. Bogotá, Instituto Caro y Cuervo. Bogotá, 1983. Escalante Polo, Aquiles (1954). El Palenque de San Basilio. Instituto Etnográfico del Atlántico. Barranquilla, 1954. Fals Borda, Orlando (1979): La historia doble de la Costa. Universidad Nacional de Colombia, Banco de la República y el Áncora Editores. Bogotá, 2002. Fanon, Frantz (1952). Piel negra, máscaras blancas. Editorial Akal. Madrid, 2009. Gutiérrez Azopardo, Idelfonso (1980) Historia del negro en Colombia isumisión o rebeldia? Editorial Nueva América. Bogotá, 1994 \& (2000). La población negra en América. Editorial El Búho. Bogotá, 2000. Gutiérrez Sanín, Francisco (1995). Curso y discurso del movimiento plebeyo 1849/1854. El Áncora editores. Bogotá, 1995. Hoyos Körbel, Pedro Felipe (2007). Bolívar y las negritudes. Momentos históricos de una minoría étnica en la Gran Colombia. Hoyoseditores. Manizales, 2007. Inikori, Joseph (2002) Africans and the industrial revolution. A study in international trade and economic development. Cambridge University Press. UK, 2002. Lamothe, Louis (1973). Alejandró Petión ayuda al Libertador Simón Bolivar. Imprenta Márquez. Cali, 1973. Llinás, Juan Pablo (1983). José Hilario López. Editorial Intermedio. Bogotá, 2007. Mosquera Mosquera, Sergio Antonio (2004). La gente negra en la legislación colonial. Editorial Lealón. Medellín, 2004. Navarrete P., María Cristina (2008) San Basilio de Palenque: memoria y tradición. Editorial Universidad del Valle. Cali, 2008. O'Leary, Daniel Florencio (1879 - 1888). Memorias. Biblioteca de autores colombianos. Bogotá, 1952. Tomo IV, p.60. Restrepo Piedrahita, Carlos (1979). Constituciones de la Primera República Liberal. Universidad Externado de 
en la presentación del contexto para la expedición de la Ley sobre Libertad de Esclavos y los personajes e historias que hicieron posible el reconocimiento del derecho a la libertad, dando lugar a la presentación de una completa relación legislativa ${ }^{27}$.

Unido a lo anterior, nos interesa resaltar aquí que esta magistrada también hizo uso del lenguaje literario del escritor afrodescendiente Manuel Zapata Olivella para resaltar dos aspectos relevantes: el origen de la ley de abolición de la esclavitud en Colombia y la

Colombia. Bogotá, 1979. 5 Tms. - (1995). Constituciones Politicas Nacionales de Colombia. Universidad Externado de Colombia. Tercera Edición. Bogotá, 2004. Splendiani, Anna María (1997) Cincuenta años de inquisición en el Tribunal de Cartagena de Indias 1610-1660. Pontificia Universidad Javeriana y el Instituto de Cultura Hispánica. Bogotá, 1997. Tisnés Jiménez, Pbro. Roberto M. (1980). Don Juan del Corral, libertador de esclavos. Banco Popular. Cali, 1980. Tovar Mora, Jorge Andrés \& Tovar Pinzón Hermes (2009). El oscuro camino de la libertad. Los esclavos en Colombia. Universidad de Los Andes. Bogotá, 2009.Trouillot, Michel-Rolph (1995). Silencing the past. Beacon Press. USA, 1995. UNESCO (1981). La Trata negrera del siglo XV al XIX: documentos de trabajo e informe de la Reunión de expertos organizada por la UNESCO en Puerto Príncipe, Haití, del 31 de enero al 4 de febrero de 1978. Ediciones del Serbal. Barcelona, 1981. Valencia Villa, Carlos Eduardo (2003). Alma en boca y huesos en costal. Una aproximación a los contrastes socio-económicos de la esclavitud. Santafé, Mariquita y Mompox 1610-1660. Instituto Colombiano de Antropología e Historia, ICANH. Bogotá 2003. Zapata Olivella, Manuel (1989). Las claves mágicas de América. Editorial Plaza \& Janes. Bogotá, 2005. p. 59 y ss. Zinn, Howard (1980): La otra historia de los Estados Unidos. Editorial Siglo XXI. México, 2006. Zuleta, Estanislao (1977). Conferencias sobre historia económica de Colombia. Hombre Nuevo Editores. Medellín, 2008. Algunas otras fuentes consultadas son citadas a lo largo de la presente aclaración de voto; en especial, ver la nota al pie número 158” (AV. M. María Victoria Calle. SC 931/09).

27 Señalamos esta ley como la de la abolición definitiva de la esclavitud, debido a que con ella se estableció la libertad inmediata de todas las personas sometidas a la esclavitud, incluso la de quienes llegaran en esta condición al territorio colombiano, sin que se hicieran efectivos los vales de manumisión que terminaron de pagarse casi diez años después de la abolición. No obstante en la aclaración de voto, María Victoria Calle nos presenta una relación de leyes anteriores a esta: encontramos leyes como la ley de vientres, expedida en 1814 por la provincia de Antioquia, mediante la cual no se abolía la esclavitud, pero se negaba a los amos la posibilidad de ser dueños de los hijos que tendrían sus esclavas. De otra parte en el marco de las diferentes Constituciones de Colombia, la Sentencia presentada, registra los siguientes datos: con la Constitución de Cúcuta de 1821: aprobó la ley de manumisión de esclavos, mediante la cual se adoptaba para todo el país la ley de vientres antes expedida en la provincia de Antioquia, pero presentaba una fórmula de incorporación gradual a la sociedad de las personas sometidas a esclavitud, persistiendo en el texto constitucional la expresión de hombres libres, que daba cuenta de que se contaba con hombres que dentro del territorio no tenían esa condición. Las Constituciones de 1830 y 1832 mantuvieron la fórmula de la de 1821. Con la Constitución de 1843 se cambió la fórmula que venía desde 1821, sobre la prohibición de la esclavitud, al menos en su aspecto formal, y se autorizó la venta de personas esclavizada, destruyendo la ilusión de quienes, al menos soñaban con la posibilidad de libertad amparados en la ley de vientres; hasta que finalmente se expide la ley de 21 de mayo de 1851 con la que se abole la esclavitud de manera definitiva, fórmula que acogen las futuras constituciones de 1853: "no habrá esclavitud ni esclavos en la Nueva Granada", la de 1858: "es prohibido al Gobierno de los Estados permitir o autorizar la esclavitud"; Constitución de 1863: "no habrá esclavos en la Nación”; Constitución de 1886: "No habrá esclavos en Colombia, el que siendo esclavo, pise territorio de la República quedará libre” ( SC-931/2009 AV. M. María Victoria Calle. Negrillas fuera de texto). 
invisibilidad a la que, desde siempre, ha estado sometida esta población. Resalta con ello la importancia que cada día se le otorga al lenguaje literario como instrumento de análisis jurídico ${ }^{28}$.

María Victoria Calle recurre a la novela Las claves mágicas de América, de Manuel Zapata Olivella, para describir el fundamento de la esclavitud, además de algunos efectos negativos de la ley de abolición de la esclavitud, desde la forma como fue concebida.

Narra Zapata Olivella: "Las ideas falsas en las que se fundó la esclavitud negra en América fueron las siguientes: que el negro resistía el trópico americano mejor que el propio nativo; que su condición étnica era superior al del indígena; que le aminoraba la carga a los indígenas; que la esclavitud católica era menos gravosa que la que habían vivido en África; que los hispanos eran más humanitarios que los anglosajones" (tomado de la SC 931/09. AV. María Victoria Calle).

Sobre las consecuencias de la Ley sobre Libertad de Esclavos el narrador cuenta: "En el campo meramente económico fue una carga que se echaba sobre las espaldas de los negros. Desnudos, carentes de herramientas de trabajo, sin tierra y expulsados de ciudades, muchos debieron resignarse a proseguir en las haciendas de los amos recibiendo una paga que ni siquiera les permitía asegurar su alimentación y como los que un siglo después seguimos observando con la marginalización de la que ha sido víctima esta población" (tomado de la SC 931/09. AV. María Victoria Calle).

28 Sobre el debate entre el derecho y la literatura y su interconexión que se discute en nuevas líneas de investigación como parte de los estudios críticos del derecho, y atendiendo a la relación que se pretende esbozar en esta obra, resulta pertinente el siguiente análisis: "Mientras que el Derecho selecciona, establece jerarquias y crea reglas, la narrativa literaria satisface un infinito de "variaciones imaginativas". Como un laboratorio de experimentos humanos, la Literatura explora un amplio espectro de posiciones, valores y representaciones, o retrae sus pasajes ante los limites más vertiginosos; mientras tanto, el Derecho se enfrenta a situaciones ya estereotipadas a las que corresponden las leyes (decretos y reglamentos). La ficción literaria cultiva la ambigüedad de sus personajes y juega con la ambivalencia de las situaciones que ella misma crea, y el Derecho solo se desarrolla a partir de generalidades y abstracciones (sentencias que establecen precedentes y reglas que a fin de evitar la arbitrariedad que trae aparejada el privilegio - usando la terminología de Rosseau-- considera a los "ciudadanos como un cuerpo"; la literatura, en cambio, se encuentra en constante movimiento, avanzando más y más sobre la singularidad de lo individual. Por lo tanto, por un lado, tenemos la conformidad de situaciones promedio, mientras que, por el otro, el misterio del destino particular... Paul Ricoeur señala que "la narración se encuentra a mitad de camino entre la descripción y la prescripción, se muestra ante nosotros como un refugio de la razón práctica; la narración constantemente reorganiza la realidad con deseos de poderla dotar de significado, y la ubica al mismo nivel de los valores introducidos por la propia historia"- Ost, 335-336 (2006). 
De otra parte, la magistrada relata hechos históricos que visibilizan a personajes que contribuyeron a la abolición de la esclavitud:

Como cuenta la historia colombiana, la historia negra de nuestro país, el primer levantamiento significativo en contra de la esclavitud y en defensa de la libertad en Colombia, se dio en los alrededores de Cartagena, bajo el mando de Benkos Biohó, uno de los principales líderes del cimarronismo y fundador de lo que luego de muchos años llegó a ser el Palenque de San Basilio. Aunque su rebelión no excluía ni cuestionaba la existencia de la institución de la esclavitud en sí misma, la desafiaba y se convertía en una amenaza para el orden colonial cuya subsistencia, como se indicó, dependía en gran parte del trabajo esclavo africano y del comercio de personas esclavizadas en las condiciones de opresión. Su ejemplo fue seguido por muchos, y dio lugar a la coexistencia de comunidades negras autónomas con gobiernos independientes, al lado del gobierno que representaba a la corona española. Aunque no fue el primer palenque que existió, si fue el que surgió de lo que podría ser el primer gran desafio. (AV. M. María Victoria Calle. SC 931/09)

Junto a lo anterior, la magistrada invita a los poderes del Estado, en el marco de su democracia participativa "a tomar medidas para reparar, abolir, superar y asegurar que no se repitan nunca más prácticas racistas pasadas y futuras". Con ello da lugar a situaciones con pocos precedentes, es decir, desde la voz de una aclaración de voto se exhorta al legislador a que cumpla con sus deberes constitucionales, no obstante la Corte no pueda, en este caso, expedir una orden directa.

Entre los argumentos que nos presenta en su aclaración de voto resaltamos su denuncia a la esclavitud:

La Ley de 21 de mayo de 1851 no es el acto mediante el cual se tomó la decisión legal de liberar a las personas esclavizadas en Colombia; es la decisión mediante la cual se puso fin al largo, complejo y doloroso proceso de manumisión que había iniciado 30 años antes [...] la libertad en Colombia se debe a muchas culturas y etnias, fue una lucha colectiva y hoy es una conquista igualmente colectiva [...] El grito de libertad e Haití dio paso a la primera república de América donde toda persona era libre [...] la historia negra muestra que si bien las ideas de libertad y de igualdad llegaron a América escondidas en medio de los galeones realistas europeos, gran parte del coraje y la determinación que permitieron llevarlas a la práctica, llegó al continente escondida en los 
galeones esclavistas provenientes del áfrica. (Sentencia C-931/2009. SV, M. María Victoria Calle)

De otra parte, la magistrada llama la atención sobre la insuficiencia de las medidas restaurativas e inclusivas a favor de esta población:

A pesar de las consagraciones normativas, los avances jurisprudenciales y las luchas adelantadas por la población afrocolombiana, la cultura política nacional no ha decantado la necesidad de reconocer la real marginación y exclusión social a la que estas comunidades han estado sometidas. En tal contexto, son también pocas y limitadas las medidas y acciones que promuevan la inclusión, la equidad y la igualdad de las comunidades negras de Colombia. (Sentencia C-931/2009. AV. M. María Victoria Calle)

Finalmente, debemos destacar que en la aclaración de voto, María Victoria Calle logra un propósito importante: nos presenta la tensión entre el discurso liberal de los nacientes Estados del siglo XVIII y la conservación de la esclavitud como institución sobre la cual se basaba el comercio ${ }^{29}$; todo esto descrito a partir de los antecedentes históricos del derecho a la libertad de las personas sometidas a la esclavitud desde la independencia de Haití, con el alto costo en vidas y económico que este país se vio obligado a pagar, y el proceso de otorgamiento de libertad a los esclavos de Colombia, descrito en las primeras constituciones de esta república.

\section{E. Fundamento del salvamento de voto}

Los magistrados Juan Carlos Henao y Luis Ernesto Vargas Silva, quienes se apartaron de la decisión mayoritaria de la Corte, consideraron que la ley demandada no había sido derogada y "sí producía efectos jurídicos en el presente”; además, señalaron que con la decisión de la Corte "se perdió una oportunidad histórica para pronunciarse sobre el alcance de la esclavitud en el país".

29 En la aclaración de voto, María Victoria Calle resalta que: "La esclavitud de personas traídas del África a América, por tanto, es una institución jurídica injusta y opresora, que se difundió de la mano de la primera revolución industrial, hasta el punto de ser un elemento fundamental de la sociedad y de la economía colonial. La República traería la promesa de libertad, pero no sin antes tener que luchar por ella" (AV. M. María Victoria Calle. SC-931/09). 
Sostuvieron que en el caso examinado se presentaban dos situaciones: la determinación de la vigencia de la ley demandada, que consideraron un asunto técnico y, de otra parte, un asunto sustancial representado en las posibilidades del juez constitucional, en su condición de garante de la Carta Política, de ordenar en el marco de sus facultades dentro de un proceso de constitucionalidad, reparaciones de injusticias históricas, en este caso respecto del crimen de esclavitud.

Para llegar a esta afirmación realizaron un análisis del alcance de las omisiones legislativas, las formas de derogatoria de las leyes y los deberes de reparación del Estado frente a injusticias históricas, que a continuación presentamos.

\section{F. Reglas de revisión de constitucionalidad frente a omisiones legislativas}

Los magistrados recordaron que la Corte, desde sus primeros pronunciamientos, aceptó la existencia de la figura llamada inconstitucionalidad por omisión, recordando que esta se presenta "cuando, por su inactividad, el legislador, no cumple con el deber de llevar a cabo los desarrollos legales necesarios para garantizar la efectividad de los enunciados normativos previstos por el constituyente”.

Además, señalaron que desde la SC-543 de 1996, la Corte distinguió las nociones de omisión legislativa absoluta y omisión legislativa relativa ${ }^{30}$, precisando que

30 Los magistrados presentaron en el salvamento de voto la siguiente reconstrucción de la línea jurisprudencial en materia de omisiones legislativas: “ $\mathrm{C}-\mathbf{4 2 7}$ de 2000, la Corte recogió y resistematizó todos los requisitos que, en varios fallos aislados, se exigieron para que se configurara una omisión legislativa relativa violatoria del derecho a la igualdad. En esta sentencia la Corte sostuvo que para poder pronunciarse sobre una omisión legislativa de este tipo, deben concurrir los siguientes requisitos: (i) debe existir una norma que excluya supuestos de hecho que, por ser similares a los que regula, deben incluirse dentro de su ámbito de aplicación; (ii) esta exclusión no debe obedecer a razones objetivas y suficientes, de manera que la omisión produzca una desigualdad injustificada y (iii) la omisión debe implicar el desconocimiento de un deber constitucional dirigido al legislador. En la sentencia C-1549 de 2000, esta Corporación reiteró lo dispuesto en las sentencias C-543 de 1996 y C-427 de 2000 al reafirmar que la Corte Constitucional debe declararse inhibida para pronunciarse de fondo sobre una demanda de inconstitucionalidad por omisión legislativa absoluta, pues uno de los requisitos para que adquiera competencia es que la omisión legislativa se refiera a una norma existente y no a la ausencia de norma. Más adelante, en la sentencia C-041 de 2002, la Corte reiteró lo dispuesto en las sentencias $\mathbf{C - 5 4 3}$ de 1996, $C-427$ de 2000 y C-1549 de 2000, pero agregó que, para que una demanda de inconstitucionalidad por omisión legislativa relativa sea admisible, el actor debe acusar el contenido normativo especificamente vinculado con la omisión, de manera que los cargos generales contra normas 
De acuerdo con esta sentencia, la omisión legislativa absoluta se presenta cuando el legislador no produce ningún precepto encaminado a ejecutar un deber concreto que le ha impuesto la Constitución. En cambio, incurre en una omisión legislativa relativa cuando, en cumplimiento del deber impuesto por la Constitución: (i) favorece a ciertos grupos, perjudicando a otros; (ii) excluye tacita o expresamente a un grupo de personas de los beneficios que otorga al resto y; (iii) al regular una institución, omite una condición o un ingrediente que, de acuerdo a la Constitución, sería exigencia esencial para armonizar con ella (V. gr. si al regular un procedimiento, se pretermite el derecho de defensa). (SC 931/09. SV. M.M. Juan Carlos Henao, Luis Ernesto Vargas Silva)

Sobre la omisión legislativa absoluta la Corte no tiene competencia para realizar revisiones porque incurriría en la esfera legislativa en la que se materializa el principio de representación democrática, mientras que sí tiene competencia para conocer casos en los que se evidencie omisión legislativa relativa.

Frente al caso específico, y atendiendo que el actor alegó omisión legislativa relativa, Henao y Vargas señalaron que para revisar textos preconstitucionales, la Corte, además de verificar los requisitos jurisprudenciales generales relacionados con las omisiones legislativas, debe tener en cuenta los siguientes:

(i) que la omisión que se alegue respecto de la ley preconstitucional persista en el tiempo; es decir, que se determine que nunca ha sido saneada por otra disposición de la misma o diferente jerarquía normativa; (ii) que esta omisión plantee un problema de relevancia constitucional, es decir, se traduzca en la inobservancia de postulados contemplados en la Constitución de 1991, y finalmente, (iii) que esta inobservancia haya generado un daño susceptible de ser

indeterminadas no son atendibles. Finalmente, en la sentencia C-185 de 2002, la Corte recogió y agrupó todas las reglas jurisprudenciales aplicables a las omisiones legislativas así: “(i) que exista una norma sobre la cual se predique necesariamente el cargo; (ii) que la misma excluya de sus consecuencias jurídicas aquellos casos que, por ser asimilables, tenían que estar contenidos en el texto normativo cuestionado, o que el precepto omita incluir un ingrediente o condición que, de acuerdo con la Constitución, resulta esencial para armonizar el texto legal con los mandatos de la Carta; (iii) que la exclusión de los casos o ingredientes carezca de un principio de razón suficiente; (iv) que la falta de justificación y objetividad genere para los casos excluidos de la regulación legal una desigualdad negativa frente a los que se encuentran amparados por las consecuencias de la norma; y (v) que la omisión sea el resultado del incumplimiento de un deber específico impuesto por el constituyente al legislador" (tomado del SV M.M. Juan Carlos Henao. Luis Ernesto Vargas Silva. SC 931/2009. Negrillas fuera de texto). 
corregido a partir de una orden de este Tribunal. (SC 931/09. SV. M.M. Juan Carlos Henao, Luis Ernesto Vargas Silva)

En este orden, determinaron que para la Corte, el estudio de la omisión legislativa dependía de la vigencia de la norma demandada, por lo cual recordaron que el ejercicio del control constitucional de normas derogadas está condicionado al cumplimiento de dos presupuestos básicos e insustituibles:

(i) que la demanda ciudadana haya sido presentada en legal forma, esto es, que reúna los requisitos mínimos señalados en el artículo 2 del Decreto 2067 de 1991 para ser admitida, y (ii) que las normas acusadas, cuya validez se cuestiona, hagan parte del ordenamiento jurídico vigente o, en su defecto, se encuentren produciendo efectos jurídicos actuales. (SC 931/09. SV. M. M. Juan Carlos Henao, Luis Ernesto Vargas Silva)

Con miras a aclarar el alcance del segundo supuesto señalaron que

Las categorías (i) validez, (ii) vigencia y (iii) eficacia, en la mayoría de las veces utilizadas indiferenciadamente, así entendidas, representan parámetros hermenéuticos útiles para constatar ciertas situaciones normativas: por ejemplo "una norma puede estar vigente pero no ser válida, para lo cual basta pensar en una ley inconstitucional pero que aún no ha sido retirada del ordenamiento por la decisión del respectivo órgano de control. Una norma puede haber sido derogada, con lo cual parece no estar vigente, pero puede seguir produciendo efectos jurídicos, es decir ser eficaz. O, finalmente, la norma puede ser válida $y$ encontrarse vigente, pero no ser eficaz, por ejemplo por tratarse de una ley que fue formalmente adoptada, que no viola ningún mandato superior, pero que establece que debe transcurrir un determinado plazo antes de que pueda ser aplicada por los operadores jurídicos. (SC 931/09. SV. M.M. Juan Carlos Henao, Luis Ernesto Vargas Silva)

Con base en las anteriores consideraciones, para los magistrados, frente a la Ley sobre Libertad de Esclavos no se ha producido derogatoria y esta sigue produciendo efectos, por lo cual no habría lugar a la declaratoria de inhibición por carencia de objeto sustracción de materia.

Sostuvieron que

Por el contrario, existe un contenido normativo, con disposiciones concretas que no comprendieron una hipótesis, esto es, la reparación por el daño sufrido 
a quienes padecieron los rigores de la esclavitud, compensación que en su momento sí fue contemplada a través de un sistema de resarcimiento a favor de los 'tenedores de esclavos', en el marco del proceso de manumisión definido en los artículos 2 al 13 y 15 al 18 de la Ley bajo examen. De esta manera, se cumple la primera de las condiciones, para que se configure una omisión legislativa relativa, es decir, (i) que exista una norma sobre la cual pueda predicarse el cargo (SC 931/09. SV. M.M. Juan Carlos Henao, Luis Ernesto Vargas Silva. Negrillas fuera de texto).

\section{G. Deber de reparación del Estado}

Los magistrados señalaron que el deber de reparar encuentra sustento constitucional en disposiciones como el artículo 90 de la Constitución, al igual que en disposiciones contempladas en instrumentos internacionales; además recurrieron a la idea de reparación histórica, sobre la que señalaron:

Como categoría de análisis, está asociada directamente con la existencia de sucesos ocurridos en el pasado que ocasionaron graves daños a grupos poblacionales determinados o determinables, pero que, a pesar del trascurso del tiempo (incluso décadas o siglos) y de la certeza sobre su antijuridicidade ilicitud, no han sido objeto de pronunciamientos o manifestaciones institucionales encaminadas a corregir sus consecuencias, por lo que en la actualidad se hacen indispensables diversas medidas de satisfacción a favor de las víctimas directas o indirectas de las conductas objeto de censura. (SC 931/09. SV. M.M. Juan Carlos Henao, Luis Ernesto Vargas Silva)

Finalmente propusieron como medidas de reparación para adoptar en el caso concreto:

- El reconocimiento de la ocurrencia de la esclavitud en Colombia como una conducta susceptible de reproche en la conciencia histórica de la nación.

- Ordenar al Congreso que, en un plazo razonable, expidiera una ley que definiera una política de reparación colectiva a la población afrodescendiente debido al crimen de esclavitud que sufrieron sus antepasados y cuyas consecuencias persisten en la discriminación que vive actualmente esa población.

Con relación a la definición de la política de reparación, los magistrados consideraron que 
[...] debería satisfacer, además de los estándares de derecho internacional recogidos y desarrollados por la jurisprudencia constitucional mencionados en esta sentencia, algunos elementos particulares, que surgen de las características propias del crimen en la historia del país. En esta medida, debió haber incluido (i) un reforzamiento en el reconocimiento institucional de la ocurrencia del crimen de esclavitud y de la falta de reparación a favor de sus víctimas; (ii) adicionalmente, un componente de reconstrucción histórica institucional de los hechos de la esclavitud, los daños causados y sus consecuencias derivadas hasta la actualidad. Esta reconstrucción histórica institucional, debió haber contado con difusión suficiente, de tal forma que le hubiera permitido a toda la población colombiana volver la mirada sobre este crimen histórico; (iii)debió incluir medidas tendientes a eliminar las desigualdades producto de la ausencia de restablecimiento del territorio ancestral de las comunidades afrocolombianas, en el marco del fortalecimiento de los mandatos de la Ley 70 de 1993; (iv) en el diseño de esta política, de acuerdo a lo dispuesto por el Convenio 169 de la OIT, el Congreso debería haber consultado previamente a las poblaciones afrodescendientes pues, de acuerdo a la jurisprudencia de esta Corporación, la preservación de la identidad diferenciada del pueblo afrocolombiano -principal acreedor de la reparación por los daños causados por la esclavitud-, y la eficacia del mandato superior de reconocimiento y protección de la diversidad étnica, se logra, entre otros, a través de la consulta previa que, en el caso de las medidas legislativas, se predica de las leyes que tengan la posibilidad de afectar directamente los intereses de las comunidades afrodescendientes". (SC 931/09. SV. M.M. Juan Carlos Henao, Luis Ernesto Vargas Silva)

\section{Finalmente, señalaron que con las órdenes propuestas}

La Corte no estaría desbordando su competencia o invadiendo la órbita de actuación del Congreso. Por el contrario, debido al profundo respeto por la estructura del Estado, por la división de poderes y la colaboración armónica entre estos, y por la libertad de configuración política del Legislador, como guardiana de los postulados constitucionales, se habría diseñado este remedio judicial, con el fin de que fuere posible brindar una reparación colectiva a la población afrodescendiente, cuyo resultado final proviniere de las deliberaciones propias del legislador como autoridad representativa de la Nación. (SC 931/09. SV. M.M. Juan Carlos Henao, Luis Ernesto Vargas Silva)

En todo el salvamento de voto, que el magistrado Juan Carlos Henao anuncia como el primer proyecto de fallo que no fue acogido por la Corte, se observa un insistente llamado a reparar a la población afrodescendiente por la injusticia histórica que contra esta población se ha cometido y que a criterio de los magistrados que salvaron el voto no ha sido reparada. Sus esfuerzos encuentran una argumentación lógica sobre el concepto de omisión legislativa 
relativa, además de disentir con el concepto mayoritario en la Corte, sobre la imposibilidad de expedir órdenes indemnizatorias a través de la revisión de constitucionalidad de la leyes, ya que plantean reparaciones morales atendiendo a los parámetros de reparación integral internacionales, aspecto que de igual forma se encuentra en la aclaración de voto de María Victoria Calle, quien exhorta al legislador y al gobierno a la expedición de leyes y políticas públicas tendientes a reparar a los afrodescendientes.

En todo este caso se observa, de manera general, un alto nivel de debate entre los magistrados de la Corte, basado en la determinación de los actuales fundamentos del Estado constitucional, orientado a consolidar el Estado constitucional en Colombia, en el marco de nuestra democracia participativa y con el innegable protagonismo de la Corte Constitucional. 


\section{CONSIDERACIONES FINALES}

1. El proceso de interpretación de la constitución colombiana está unido a un proceso de interpretación social, que se evidencia en el activismo político de ciudadanos que, haciendo uso de la acción pública de constitucionalidad, llegan a controvertir decisiones legislativas, incluso de siglos anteriores. Esto refleja que el constitucionalismo, como modelo jurídico-político, ha provocado cambios significativos en las últimas dos décadas en Colombia, comprometiendo en su proceso de consolidación a todas las personas que encuentran en la Corte Constitucional un espacio para discutir la labor legislativa y gubernativa en torno al proceso de formación de las leyes.

2. La Corte Constitucional colombiana se ha convertido, a partir de sus decisiones, en un ejemplo para el constitucionalismo democrático, que no solo se orienta al cumplimiento de los parámetros de interpretación constitucional, sino que se extiende a procesos pedagógicos, de forma que el análisis de sus sentencias se convierte en un proceso de enseñanza y aprendizaje de aspectos jurídicos, políticos, históricos y sociales. Con este alcance es acertado afirmar que la Corte está materializando el principio constitucional de enseñanza de la Constitución de manera integral.

3. En su función de interpretación la Corte hace uso de otros lenguajes como la literatura, dando lugar a que el paradigma garantista de esta corporación se expanda en reconstrucciones históricas desde diferentes paradigmas.

4. En el caso concreto analizado se pone de presente la mixtura en torno a las interpretaciones de la Constitución. Frente una Corte integrada por nueve magistrados, se encuentra el salvamento de voto de dos de ellos y la aclaración de voto de otro de sus miembros; esto refleja un importante e interesante proceso de disertación y el alto compromiso de estos jueces con su función garantista.

5. La sentencia analizada es un ejemplo para el constitucionalismo universal del poder de interpretación de la Corte colombiana, que se ha convertido en un referente obligado para el estudio de 
las leyes de los más débiles y del garantismo judicial en el marco del nuevo constitucionalismo latinoamericano.

6. La decisión de la Corte, en el caso objeto de análisis, aunque inhibitoria, produce importantes consecuencias en la esfera legislativa y gubernamental, por cuanto se constituye en un instrumento de presión para la expedición de leyes y políticas públicas orientadas a la reparación de la población afrodescendiente por la injustica histórica a la que ha estado sometida. A pesar de que no se haya expedido una orden directa y, como lo anotaron los magistrados Juan Carlos Henao y Luis Ernesto Vargas Silva, se haya perdido la oportunidad histórica de denunciar el crimen de la esclavitud en Colombia. 


\section{BIBLIOGRAFÍA}

\section{Libros}

A. Robert \& E. Bulygin, La pretensión de corrección del derecho: la polémica sobre la relación entre derecho y moral, Ed. Universidad Externado de Colombia, Serie de Teoría jurídica y filosofía del derecho, No 18, Colombia (2001).

C. Meillassoux, Antropología de la esclavitud, Ed. Siglo Veintiuno Editores, México (1990).

F. Cabezas, Comp., Castigos y torturas en la afro diáspora para el nuevo mundo, Ed. Prado, Colombia (2011).

G. Aguilar, Justicia constitucional y modelos de reconocimiento de los pueblos indígenas, Ed. Porrúa, México (2011).

G. Marcilla, Ed., Constitucionalismo y garantismo, Ed. Universidad Externado de Colombia, Serie de Teoría jurídica y filosofía del derecho, No. 53, Colombia (2009).

G. Zagrebelsky, El derecho dúctil, Ed. Trotta, Madrid (2007).

H. Zinn, La otra historia de los Estados Unidos, Ed. Siglo Veintiuno Editores, México (2010).

L. Ferrajoli, Democracia y garantismo, Ed. Trotta, Barcelona (2009).

L. Prieto Sanchís, Constitucionalismo y Positivismo, $2^{\text {a }}$ ed., Ed. BEFDP, México (1999).

M. Carbonell, Elementos de derecho constitucional, $2^{\mathrm{a}}$ reimpresión, Ed. Fontamara, México (2009).

M. Carbonell, en: G. Zagrenelsky, Ed., Historia y Constitución, Ed. Trotta, Madrid (2011).

M. L. Cruz, La Constitución como orden de valores, problemas jurídicos y políticos, Ed. Comares, Granada (2005).

P. Comanducci, Democracia, derechos e interpretación jurídica, Ed. Ara, Perú (2010).

P. Haberle, Pluralismo y constitución, Ed. Tecnos, España (2002).

R. Arango, Derechos, constitucionalismo y democracia, Universidad Externado de Colombia, Serie de Teoría jurídica y filosofía del derecho, No 33, Colombia (2004).

R. Guastini, Teoría e ideología de la interpretación constitucional, $2^{\mathrm{a}}$ Ed., Trotta, Madrid (2010).

R. Viciano \& R. Martínez Dalmau, Derechos y garantías: la ley del más débil, $7^{\mathrm{a}}$ ed., Trotta, Madrid (2010).

Teoría del discurso y derechos humanos, Universidad Externado de Colombia, Serie de teoría jurídica y filosofía del derecho, No. 1, Colombia (2009).

Tres discursos sobre la teoría de los derechos fundamentales y la teoría de los principios, Universidad Externado de Colombia, Serie de teoría jurídica y filosofía del derecho, No. 28, Colombia (2003). 


\section{Contribuciones en obras colectivas}

R. Viciano \& R. Martínez Dalmau, Fundamento teórico del nuevo constitucionalismo latinoamericano, en: R. Viciano Pastor, Estudios sobre el nuevo constitucionalismo latinoamericano, E. Tirant Lo Blanch, Valencia (2012).

\section{Revistas}

F. Ost, El reflejo del derecho en la literatura, Doxa, Cuadernos de Filosofía del Derecho, No. 29 (2006). 
